\title{
LOW-LEVEL LIQUID SCINTILLATION COUNTING IN AN UNDERGROUND LABORATORY
}

\section{ULRICH SCHOTTERER and HANS OESCHGER}

\author{
Physics Institute, University of Bern, Sidlerstrasse 5, \\ CH-3012 Bern, Switzerland
}

\begin{abstract}
A commercial liquid scintillation counter (LSC) was tested for its ability of low level counting (LLC) in two underground laboratories $(70 \mathrm{~m}$ of water equivalent cover). Reduction of total background and background components compared to the normal counting laboratory ( $5 \mathrm{~m}$ w.e. cover) up to a factor of 9 depending on the energy range and the shielding of counting cell and laboratory walls were obtained. First experiments with a large volume cell $(50 \mathrm{cc})$ led to a modern ${ }^{14} \mathrm{C}$ net effect of $425 \mathrm{cpm}$ and a corresponding background of $1.6 \mathrm{cpm}$.
\end{abstract}

\section{INTRODUCTION}

Since the routine use of the underground laboratory in our institute in 1975, mainly proportional counters were in operation. The measured background reductions (Oeschger and Wahlen, 1975; Loosli, Heimann, and Oeschger, 1979) and the need for higher sample throughput for environmental ${ }^{3} \mathrm{H}$ measurements led to the purchase of a commercial LSC. Foregoing tests of different instruments indicated the possibility of direct counting (without previous enrichment) with sufficient precision. For 15 months, an instrument (Intertechnique SL 4000) was in routine operation, and the statistical treatment of standard and background samples (over 150 individually prepared samples) resulted in a stability and reproducibility comparable to gas counter systems. This led to the experiments with large volume cells since counting volume and shielding seem to be the limiting factor of a commercial instrument.

\section{EXPERIMENT}

The measurements consisted of two parts. In one step, various background spectra of the LSC without modification in three different laboratories were measured at $8^{\circ} \mathrm{C}$. Laboratory $\mathrm{U} 2$ is situated in the basement of our institute and is covered by approximately $5 \mathrm{~m}$ of water equivalent in the form of normal concrete. The laboratories, $\mathrm{TL}_{1_{4} \mathrm{C}}$, with $40 \mathrm{~cm}$ of special low activity concrete, and $\mathrm{TL}_{\mathrm{HE}}$, are situated in the sandstone $(70 \mathrm{~m}$. w.e.) below our institute.

In a second step, the two photomultipliers (PM) were removed from the instrument to a blackbox of styropor. The entire electronics remained in use from the LSC. Instead of a commercial counting vial, a special sample container, in the form of a disc, was constructed out of Delrin to use the whole surface of the PM (2-inch diameter). The distance of the PM's and the wall thickness of the container were the same as in the commercial version $(32 \mathrm{~mm}$ and $1.5 \mathrm{~mm})$, providing a total container volume of $\sim 50 \mathrm{cc}$. The whole, very provisional "counting chamber" was situated in our routine lead shield as seen in figure 1 . To obtain reduction factors when using an underground laboratory, measurements were performed in identical shields in the laboratories $\mathrm{U} 2$ and $\mathrm{TL}_{14 \mathrm{C}}$. The analog signal of the system was connected to a multichannel to record the spectra. These measurements were performed 
at ambient temperature $\left(20-25^{\circ} \mathrm{C}\right)$. The following counting configurations were used:

Black vial-the PM's cannot see each other. Coincident pulses may originate from electronic noise, random coincidences, cosmic radiation, and radiation from the surroundings. Since the "natural" contribution in the ${ }^{3} \mathrm{H}$ channel is very small $\left(\sim 0.07 \mathrm{cpm}\right.$ in the $\left.\mathrm{TL}_{{ }^{14} \mathrm{C}}\right)$ this version was also used to isolate electronic noise from radiation processes. Random coincidences are negligible at $20 \mathrm{~ns}$ coincidence time and modern lownoise PM's.

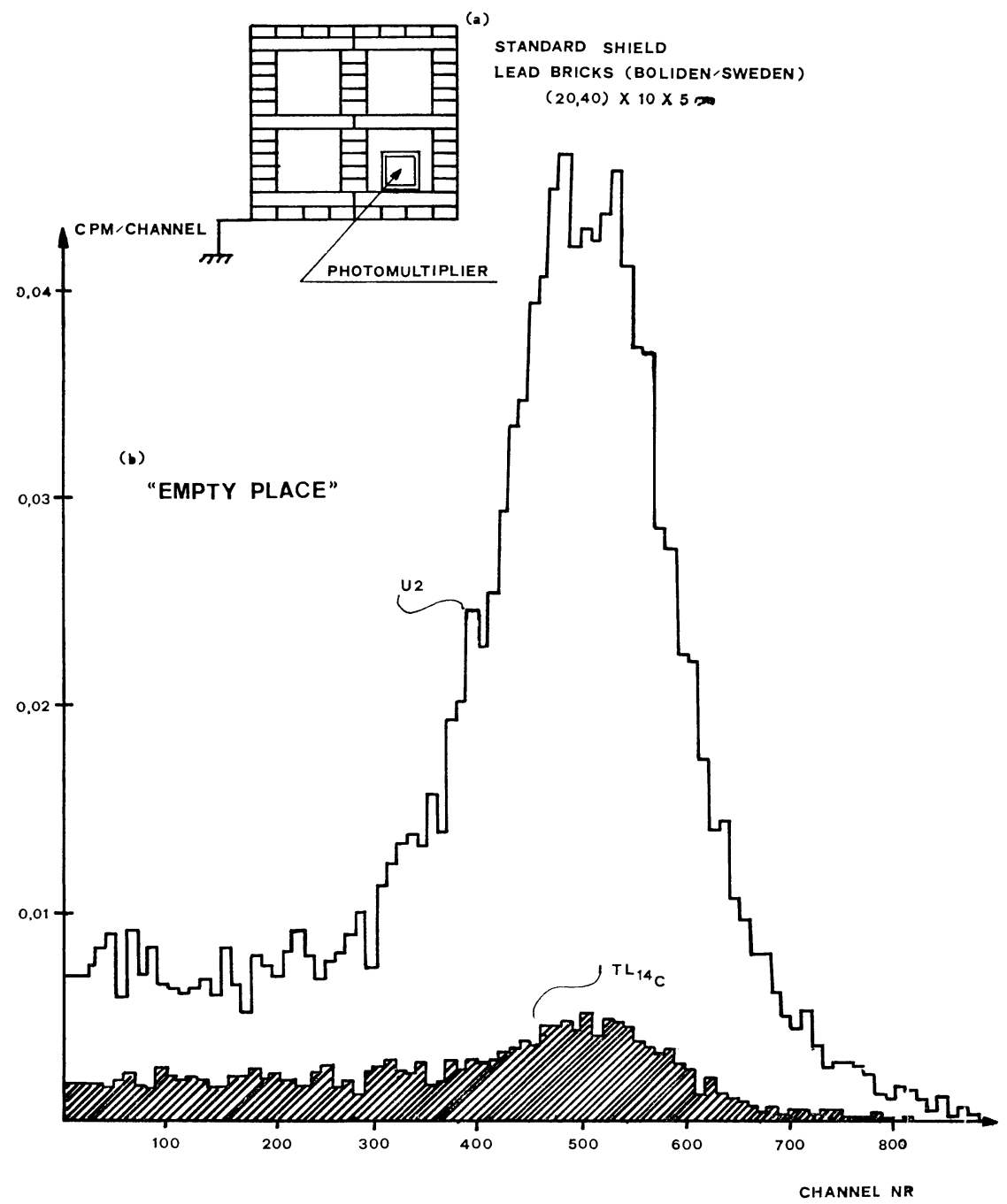

Fig 1. Standard shield of our gas counter systems, in which the experiment was performed (a) and energy spectrum in the empty large volume counting chamber in the laboratories $\mathrm{U} 2$ and $\mathrm{TL}_{14 \mathrm{C}}$ (b). 


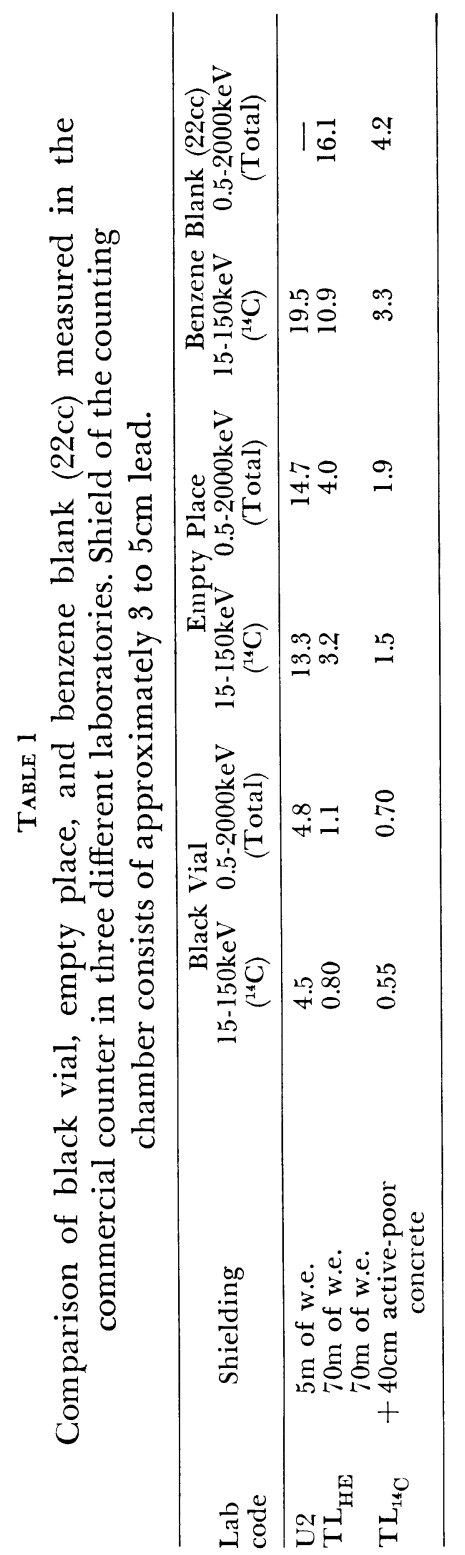


Empty place - the PM's see each other, but there is no sample container between them. The pulses originate from the black vial configuration in addition to optical cross talk of the multipliers. The count rate includes all radiation processes in the counting chamber and it is a main source of the resulting background.

Benzene blank-p.a. benzene from Merck was used with $4 \mathrm{~g}$ PPO and $0.2 \mathrm{~g}$ POPOP per 1 . The commercial polyethylene vial was filled with $22 \mathrm{cc}$ and the large volume container with $49 \mathrm{cc}$.

\section{RESULTS AND DISCUSSION}

Tables 1 and 2 list results of prime interest in ${ }^{14} \mathrm{C}$ counting. Since the experiments started shortly before the conference, the values have a rather informational character for people who are interested in ${ }^{14} \mathrm{C}$ LSC. No reduction factors are given for the commercial instrument in table 1, since the lead shield is obviously too thin to eliminate the $\gamma$-radiation from the surrounding sufficiently. A comparison of a "normal" and an underground laboratory with active-poor walls would be misleading. Major background sources in LSC are $\gamma$-radiation from the surroundings (clean counter material provided) and radiation from muon interaction ( $\gamma$-rays and Cerenkov radiation). Significant reduction from muons and muon-induced background components can only be achieved by underground laboratories (an equal shield in clean heavy material on ground level would be uneconomical). The laboratories $\mathrm{TL}_{14}$ and $\mathrm{TL}_{\mathrm{HE}}$ have the same muon shield but differ in the wall material: $40 \mathrm{~cm}$ of special concrete in $\mathrm{TL}_{1{ }_{14}}$ yield in a $\gamma$ reduction factor of 5 to 13, depending on the energy range (Neftel, 1976) measured with an unshielded $\mathrm{Ge}-(\mathrm{Li})$ detector. This may explain the different results in table 1 between $T L_{14}$ and $T L_{\mathrm{HE}}$, the latter reducing the advantage of an underground laboratory up to a factor of 4 (benzene blank, total energy range) because of the unshielded radiation of the walls. For commercial instruments, a first effective step in reducing background is, therefore, the shielding of laboratory walls with activepoor concrete, since an increase of the shield of the counting chamber is often very complicated.

Measurements in the large volume cell surrounded by 10 to $20 \mathrm{~cm}$ active-poor lead are shown in table 2. In this case, the $\gamma$-radiation of

\section{TABLE 2}

Comparison of black vial, empty place and benzene blank $(49 \mathrm{cc})$ measured in the large volume counting chamber in the laboratories $\mathrm{U} 2$ and $\mathrm{TL}_{{ }_{14} \mathrm{C}}$.

The shield of the counting chamber is 10 to $20 \mathrm{~cm}$ lead (see fig 1 ).

\begin{tabular}{|c|c|c|c|c|c|c|}
\hline \multirow[b]{2}{*}{$\begin{array}{l}\text { Lab } \\
\text { Code }\end{array}$} & \multicolumn{2}{|c|}{ Black Vial } & \multicolumn{2}{|c|}{ Empty Place } & \multicolumn{2}{|c|}{ Benzene Blank (49cc) } \\
\hline & $\begin{array}{c}15-150 \mathrm{keV} \\
\left({ }^{14} \mathrm{C}\right)\end{array}$ & $\begin{array}{l}0.5-2000 \mathrm{keV} \\
\quad \text { (total) }\end{array}$ & $\begin{array}{c}15-150 \mathrm{keV} \\
\left({ }^{14} \mathrm{C}\right)\end{array}$ & $\begin{array}{c}0.5-2000 \mathrm{keV} \\
\quad \text { (total) }\end{array}$ & $\begin{array}{c}15-150 \mathrm{keV} \\
\left({ }^{14} \mathrm{C}\right)\end{array}$ & $\begin{array}{l}0.5-2000 \mathrm{keV} \\
\quad \text { (total) }\end{array}$ \\
\hline U2 & 0.6 & 1.5 & 9.0 & 12.9 & 7.8 & 16.3 \\
\hline$T L_{14} \mathrm{C}$ & 0.08 & 0.3 & 1.2 & 1.9 & 1.6 & 3.7 \\
\hline $\begin{array}{l}\text { Reduction- } \\
\text { factor }\end{array}$ & 7.5 & 5 & 7.5 & 6.8 & 4.9 & 4.4 \\
\hline
\end{tabular}




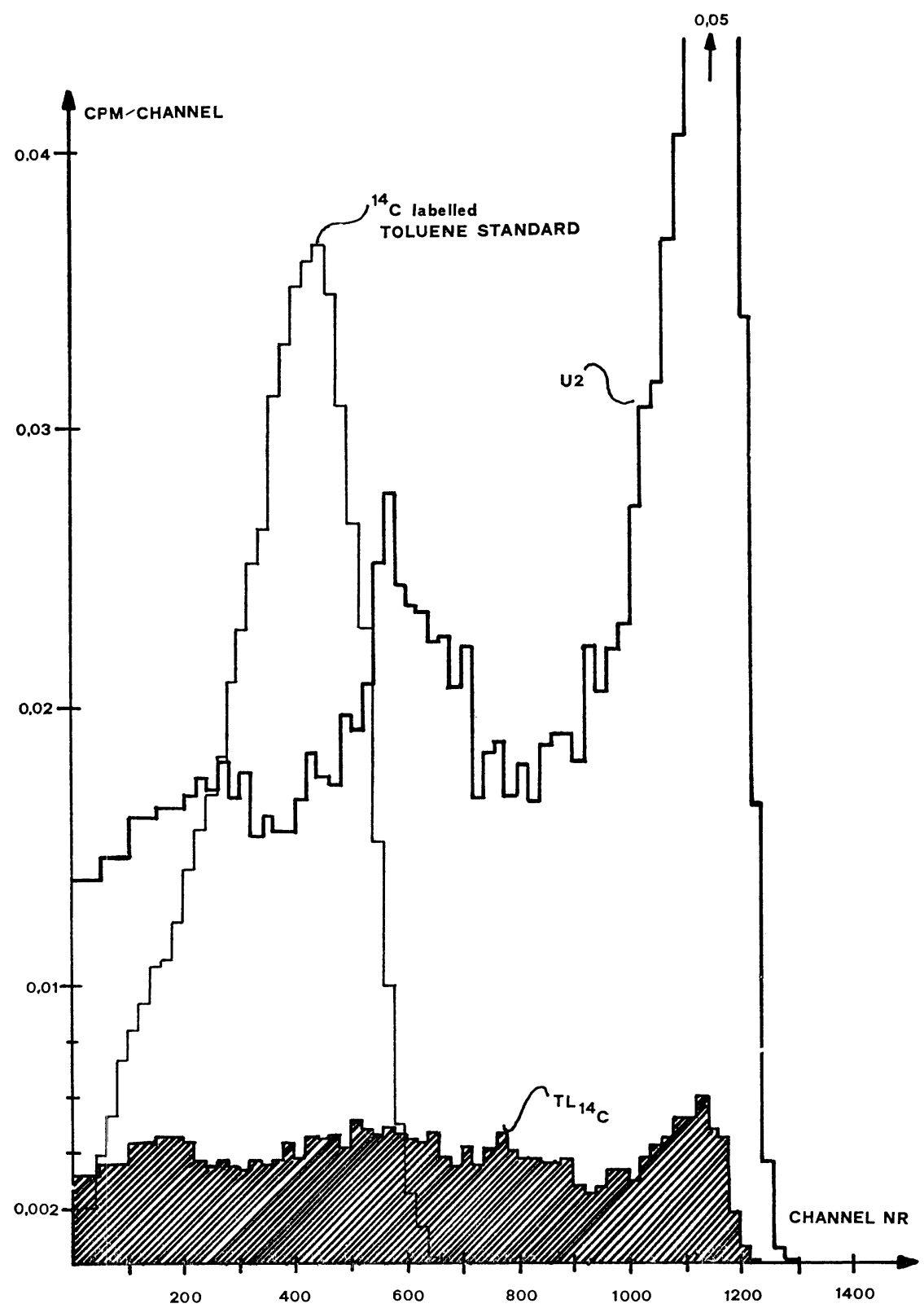

Fig 2. Energy spectrum in $49 \mathrm{cc}$ benzene blank in the $\mathrm{U} 2$ and $\mathrm{TL}_{\mathrm{14}_{\mathrm{C}}}$ laboratory. 
the surrounding shield plays a minor role compared to the muon induced component. Figure 1 compares the energy spectrum in the empty counting chamber in laboratories $\mathrm{U} 2$ and $\mathrm{TL}_{14}$. The reduction in the ${ }^{14} \mathrm{C}$ range (up to channel 700 ) is a factor 7.5 (also for the black vial, as seen in the table) in the peak region even more than 9 , which is close to the expected muon reduction of about 11 . The situation with the sample liquid is more complex (fig 2). The energy spectrum is smoothed $\left(\mathrm{TL}_{14 \mathrm{C}}\right)$ or split into different peaks due to different secondary effects (wave length shifting, optical behavior of the liquid and the counting chamber, etc) which we did not study in detail up to now: in the U2 laboratory the count rate in the ${ }^{14} \mathrm{C}$ range of the empty chamber is even higher than for the benzene blank (see table 2).

The advantage of the massive lead shield (and the possible absence of radioactivity in the counting chamber itself) compared to the com-

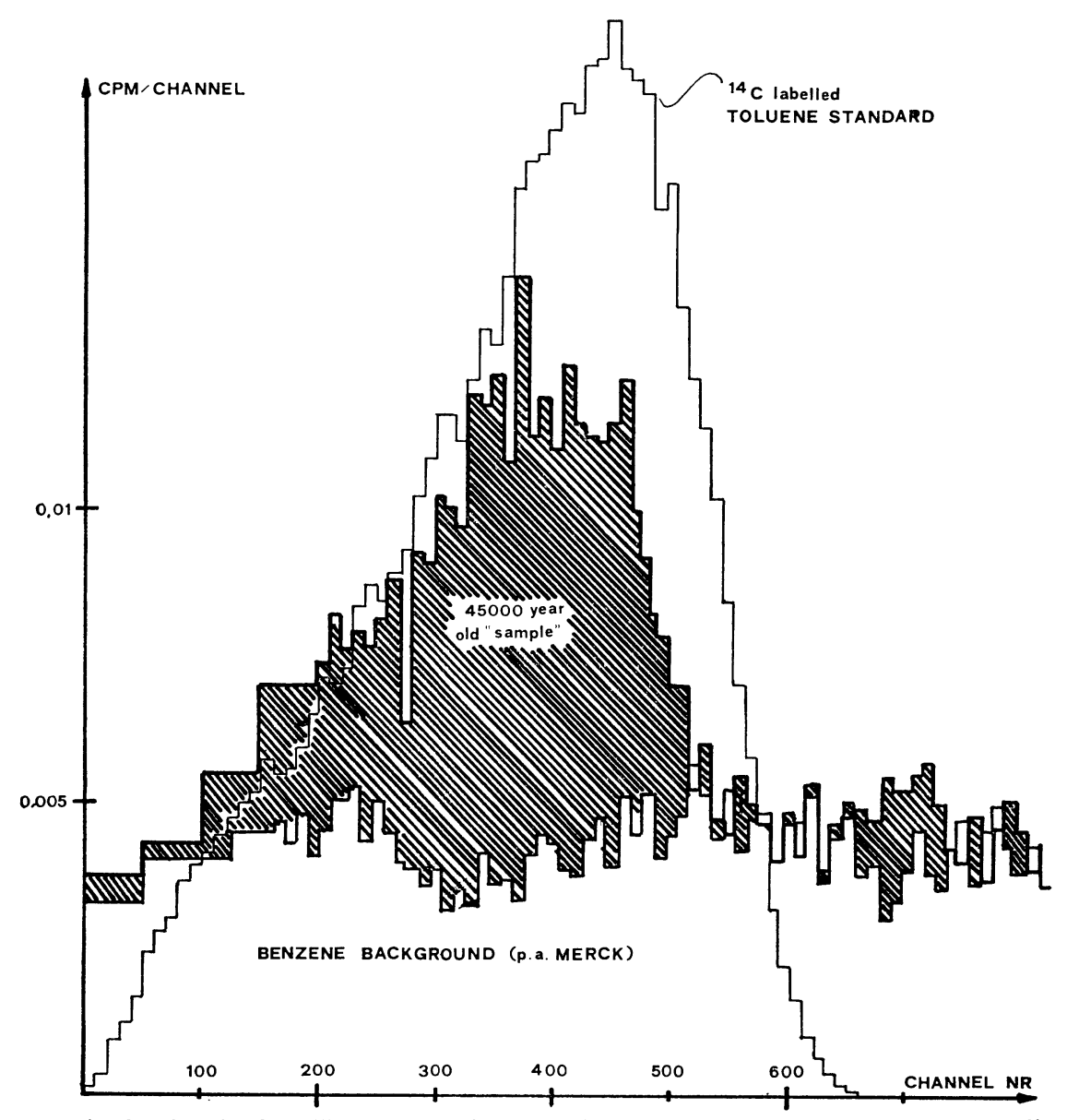

Fig 3. Signal of a 45,000 year old "sample" prepared with diluted NBS oxalic acid over its background after 1400 min counting time. 
mercial counter is obvious in the U2 laboratory also, even excluding a volume effect (49cc compared to 22cc of benzene) which we did not measure. Since we are not set up for synthesizing benzene, we measured NBS oxalic acid prepared in another laboratory. Although we had to dilute (by weighing) because of the great quantity that we needed, the $11.2 \mathrm{cpm} / \mathrm{g}$ carbon (Schütz, pers commun) are comparable with our measured $10.8 \mathrm{cpm} / \mathrm{g}$ of carbon in similar window settings. This leads to an (extrapolated) modern ${ }^{14} \mathrm{C}$ net effect of $\sim 425 \mathrm{cpm}$.

\section{CONCLUSION}

Excluding possible difficulties in preparation of large amounts of benzene (which we cannot weigh) the advantage in ${ }^{14} \mathrm{C}$ counting in an underground laboratory with sufficient shielding is shown in figure 3: the signal of a 45,000-year-old "sample" (diluted NBS oxalic acid) after 1400 min counting time over its background. The slight shift between the sample and the toluene standard is due to quenching. Several blank measurements with active-free benzene showed a very good reproducibility in the $\mathrm{TL}_{14_{\mathrm{C}}}$ (the blank spectrum is very uniform). In the future, we plan to lead this very provisional experiment to a simple large volume counter with a sample changer.

\section{ACKNOWLEDGMENTS}

Thanks are due Dr Schütz and his laboratory (Reckenholz, CH) for preparing the NBS standards, to $\mathrm{H}$ Riesen, for constructing the provisional vials and counting chamber, and to NUCLETRON, Lausanne, for support with the LSC. The research project is supported by the Swiss National Science Foundation.

\section{REFERENCES}

Oeschger, Hans and Wahlen, M, 1975, Low level counting techniques: Ann rev nuclear sci, v 25, p 423-463.

Loosli, H H, Heimann, Martin, and Oeschger, Hans, 1980, Low-level gas proportional counting in an underground laboratory, in Stuiver, Minze and Kra, Renee, eds, Internatl radiocarbon conf, 10th, Proc: Radiocarbon, v 22, no. 2, p 461-469.

Neftel, A, 1976, Zum Nulleffekt im Tieflabor: Lizentiatsarbeit, Univ Bern. 